\title{
CATALYTIC GOLD NANO-PARTICLES
}

\author{
M.B. Cortie ${ }^{1}$ and E. van der Lingen ${ }^{2}$ \\ ${ }^{1}$ Institute for Nanoscale Technology, University of Technology Sydney, PO Box 123, Broadway, NSW 2007, Australia \\ ${ }^{2}$ Physical Metallurgy Division, Mintek, Private Bag X3015, Randburg 2125, South Africa
}

\begin{abstract}
Although gold is the most inert of all metallic elements, it has interesting properties as a heterogeneous catalyst. There are a number of curious aspects to catalysis by gold that are currently attracting academic investigation, while the observation that gold-based catalysts are active at room temperature and below is driving considerable industrial interest. However, much is still not understood about these catalysts and, for example, apparently similar preparation techniques result in activities of hugely varying magnitude. In the present paper we assess the known phenomenology of heterogeneous catalysis by gold, with particular reference to the material properties of the individual nano-particles of catalyst and the many disagreements in the literature. Even the structure of the nano-particles is uncertain, with claims being made for truncated octahedra, cub-octahedra, icosahedra, various kinds of decahedra, and amorphous structures. As far as uncertainty concerning the mechanism of catalysis is concerned, we show that the situation has not yet been resolved, with evidence that catalysis can proceed even in the absence of either a discrete particulate morphology or an oxide support. One possibility is that more than one mechanism applies. Alternatively, the explanation may be that the activity of gold as a catalyst is determined only by the availability of surface gold atoms with low coordination numbers and an associated electron density suitable for whatever reaction is being catalysed. In this case, the role of the oxide support and of gold particle size and structure is indirect, and they would serve mainly to modulate the specific surface area of the gold, and the electronic configuration of its surface atoms.
\end{abstract}

\section{INTRODUCTION}

Although the catalytic properties of platinum were discovered by Michael Faraday in 1835, and those of the transition metals and their oxides soon after, it has been widely believed until quite recently that gold was too inert to be useful as a catalyst ${ }^{1}$. This was despite an isolated indication to the contrary in $1906^{\otimes}$. The paradigm was overturned in the mid-1980s by the work of Masatake Haruta at the Osaka National Research Institute in Japan [2,3], and Graham Hutchings, then at University of the Witwatersrand in South Africa [4]. Their work showed for the first time that gold was a surprisingly active catalyst provided that it was prepared according to specific, and somewhat mysterious, recipes. These early endeavours have laid the basis for an ever-expanding study of catalytic gold, and it is now generally (but not universally [5]) accepted that the special property of catalytically active gold is that it presents to the chemical environment as discrete, nano-scale gold particles in a very particular size range, variously considered to be 2 to $3 \mathrm{~nm}[6,7]$ or 3 to $5 \mathrm{~nm}[1,8,9]$. However, an optimum range of 7 to $8 \mathrm{~nm}$ for some reactions has also been claimed [10] and activity has even been reported for particles in the 30 to $50 \mathrm{~nm}$ range $[11,12,13]$. While the upper cut-off of activity appears to be for particles of $50 \mathrm{~nm}$ diameter, the lower cut-off appears to be close to $2 \mathrm{~nm}$ $[7,14]$.

The question of whether it is some special property of these nano-phase particles that confers on them a catalytic ability, or whether it is the result of an interaction between particle and support, or even whether particle size and support are only indirect factors and it is some special site on the surface of the gold that does the work, is not yet agreed in the literature. In the present paper we will review the phenomenology of heterogeneous catalysis by gold nano-particles, with a particular emphasis on how this is influenced by the nano-scale properties of gold, and we will attempt to resolve some of the uncertainty in the literature.

\footnotetext{
${ }^{\otimes}$ W.A. Bone and R.V. Wheeler, Phil. Trans., vol.206A, 1906, p.1, cited by Bond ${ }^{1}$
} 


\section{CATALYTIC PROPERTIES OF GOLD}

\subsection{Preparation of active gold catalysts}

In general, the widely used catalysts based on the platinum group metals are produced by impregnating a porous ceramic substrate with a solution of metal salt, followed by drying, and then thermal decomposition to produce a dispersion of metallic particles loaded onto a meso-porous oxide or other support. In addition, optimum use of such catalysts generally requires some form of chemical reduction of the metallic particle immediately prior to use. As a general observation, attempts to prepare active gold-based catalysts by this route produce indifferent results [9]. For example, Bamwenda et al [15] reported that $\mathrm{Au} / \mathrm{TiO}_{2}$ prepared by impregnation had very low $\mathrm{CO}$ conversion compared with catalyst prepared by depositionprecipitation. It is this idiosyncrasy of gold-based catalysts that more than any other probably explains why they have been disregarded for so long. However, a modified impregnation method using hydroxide as support and gold phosphine complexes as precursor compounds has resulted in catalysts with activities similar to those prepared by co-precipitation [16] showing that there is no a priori reason why active gold catalysts cannot be prepared by impregnation.

It has become abundantly evident that gold only becomes catalytically active in very particular instances. However, there appear to be more than one means to achieve this special state. The common denominator that links successful preparation routes from the others still not absolutely established, despite some systematic studies, such as the recent one by Wolf and Schüth [17], and there are still many interesting disagreements in the literature [18]. However, one fact that is agreed is that active gold catalysts may be reliably produced by attaching nanoparticles of gold to the surface of particular transition metal oxides by co-precipitating the transition metal and the gold (possibly in the form of thermally unstable hydroxides or carbonates) followed by a calcination treatment, or by deposition-precipitating the $\mathrm{Au}(\mathrm{OH})_{3}$ onto a previously synthesised oxide substrate, followed by a calcination treatment. Details of the preparation techniques for successful catalysts vary widely between laboratories, with the effects of aging, stirring, washing, order in which reactants are added, temperature, concentration of reactants, and calcining conditions, for example, all evidently important, but still with such poor consistency and reproducibility that a completely convincing overarching hypotheses has yet to be formulated [17]. However, even the above paradigm is evidently not completely inclusive of all gold heterogeneous catalysts made by aqueous precipitation, and some workers have found that the best results are actually obtained for mixtures of $\mathrm{Au}(\mathrm{OH})_{3}$ nanoparticles on transition metal hydroxides
$[19,20]$ (i.e. neither $\mathrm{Au}^{0}$, oxides or a calcination treatment were actually required).

\subsection{Oxidation of carbon monoxide}

Gold-based catalysts have been shown to have the best low-temperature activity for $\mathrm{CO}$ oxidation of all catalysts [21] and, at low temperatures, exceed the activity of catalysts based upon platinum group metals by about a factor of five for this reaction [9]. This reaction is of great interest in terms of the purifying of indoor and in-vehicle air, and a large number of studies have been conducted (e.g. see Thompson \& Bond [18] for a review of the literature). In most of these studies the gold nano-particles, generally of between 2 and 10 $\mathrm{nm}$ in size, have been supported on metal oxides of various sorts. There is a degree of disagreement on details, but the broad consensus is that reducible oxides of variable stoichiometry such as $\mathrm{MnO}_{\mathrm{x}}, \mathrm{TiO}_{\mathrm{x}}, \mathrm{FeO}_{\mathrm{x}}$ and $\mathrm{CoO}_{\mathrm{x}}$ somehow contribute significantly to the catalytic activity of the gold, whereas oxides of fixed stoichiometry, for example $\mathrm{Al}_{2} \mathrm{O}_{3}$, do not [5,21]. Gold on $\mathrm{Fe}_{2} \mathrm{O}_{3}$ is active [3] for this reaction at temperatures as low as $197 \mathrm{~K}\left(-76^{\circ} \mathrm{C}\right)$, a fact which helped to alert the wider scientific community to the unusual properties of gold nano-particles. Excellent and sustained activity is also obtained when catalytic gold nano-particles are combined with the already catalytic mixed $\mathrm{MnO}_{\mathrm{x}}-\mathrm{CuO}_{\mathrm{y}}$ oxide ('hopcalite') [13,22].

The selective oxidation of $\mathrm{CO}$ in $\mathrm{H}_{2}$-rich streams is also being studied by several groups, because of this reaction's probable importance in future PEM fuel cell systems for motor vehicles. In these systems it is expected that the $\mathrm{H}_{2}$ needed for the fuel cell will be obtained by reforming a hydrocarbon fuel in an onboard reformer system. Unfortunately, a small percentage of $\mathrm{CO}$ is inevitable in the resulting reformed gas and this species is a potent poison of the PGM anode catalysts of the fuel cell. Therefore, CO must be somehow removed from the gas stream and selective oxidation over a gold-based catalyst is one of the possibilities $[21,23]$.

\subsection{Oxidation or partial oxidation of alkanes and alkenes}

Gold-based catalysts are capable of catalysing the oxidation of methane $\left(\mathrm{CH}_{4}\right)$, propane $\left(\mathrm{C}_{3} \mathrm{H}_{8}\right)$ and propene $\left(\mathrm{C}_{3} \mathrm{H}_{6}\right)$. For example, $\mathrm{Au}$ on $\mathrm{Co}_{3} \mathrm{O}_{4}$ is able to match the activity of commercial catalysts based on $\mathrm{Pd} / \mathrm{Al}_{2} \mathrm{O}_{3}$ for alkanes, but is not as effective for alkenes (see Thompson [9] for a review of these phenomena). On the other hand, it has been claimed that gold catalysts are uniquely selective for the partial oxidation of propene to propene oxide [6]. For example, $\mathrm{Au} / \mathrm{TiO}_{2}$ in a feed consisting of $10 \%$ propene, $10 \%$ oxygen, $10 \%$ hydrogen and $70 \% \mathrm{Ar}$, gives $99 \%$ selectivity to propene oxide with $1.1 \%$ propene conversion [24]. Curiously, the nature of the reactions catalysed by gold appears to depend on the particle size. For example, it has been reported that particles above $2 \mathrm{~nm}$ in size 
facilitate the oxidation to propene oxide, whereas when they are below $2 \mathrm{~nm}$ in size they cause its reduction to propane [25].

\subsection{Water gas shift and steam reforming}

The water gas shift (WGS) reaction, $\mathrm{CO}+\mathrm{H}_{2} \mathrm{O} \rightarrow$ $\mathrm{CO}_{2}+\mathrm{H}_{2}$, is widely used in industry, primarily to generate $\mathrm{H}_{2}$. Generally, $\mathrm{Fe}$ - or $\mathrm{Cu}$-based catalysts are used. However gold catalysts are also active for the WGS reaction and can exceed the available commercial catalysts in activity $[6,14]$.

Obviously $\mathrm{H}_{2}$ is involved in the WGS reaction, but details of its interaction with gold nano-particles is controversial, with Andreeva ${ }^{14}$ and the group of Haruta (e.g. ref. [26]) claiming evidence that the particles could dissociate $\mathrm{H}_{2}$ and others (e.g. ref. [27]) claiming that the clusters have a negligible affinity for $\mathrm{H}_{2}$ and will not disassociate it .

The efficacy of gold catalysts in the related steam reforming reactions, e.g. $\mathrm{C}_{3} \mathrm{H}_{8}+\mathrm{H}_{2} \mathrm{O} \rightarrow 3 \mathrm{CO}_{2}+10 \mathrm{H}_{2}$ has not yet been as much discussed in the literature, however these reactions have great relevance for any future PEM-powered motor vehicle, and bear a closer look.

\subsection{Reactions involving NO$_{x}$}

Nitric oxide (NO) and all the other $\mathrm{NO}_{\mathrm{x}}$ gases are troublesome components of the exhaust gas produced by petrol and diesel engines. The most obvious way to get rid of them is to reduce them to $\mathrm{N}_{2}$ using unburnt $\mathrm{CO}, \mathrm{H}_{2}$ or hydrocarbons in the exhaust gas. This can be achieved using conventional platinum group metal (PGM) catalysts using a 'three-way' catalyst system. However, this becomes more difficult when the engine is operated under 'lean' conditions, that is, with 10 to $20 \%$ more $\mathrm{O}_{2}$ than is required to combust all the fuel. Some petrol engines, and many diesel engines, operate under lean burn conditions.

Ueda and Haruta have shown [28] that under oxygenfree conditions gold-based catalysts easily outperform those based on the PGMs for the reduction of NO by CO. Considerable activity is shown even at only $27^{\circ} \mathrm{C}$ with complete conversion to $\mathrm{N}_{2}$ occurring at about $150^{\circ} \mathrm{C}$. However, as expected, reduction of $\mathrm{NO}$ to $\mathrm{N}_{2}$ under the more commercially-interesting lean-burn conditions is more difficult, with gold catalysts generally not being as active at the lower temperatures as the PGM-based ones. However, gold nevertheless has some advantages, being more selective for $\mathrm{N}_{2}$ than the PGM catalysts and less susceptible to the deleterious effects of moisture than most ordinary transition metal oxide catalysts. Reduction of NO by hydrocarbons e.g. propene is more complex, with poor activity being exhibited over $\mathrm{Au} / \mathrm{Al}_{2} \mathrm{O}_{3}$ in the absence of $\mathrm{O}_{2}$ and much improved conversion when the $\mathrm{O}_{2}$ content of the reaction stream is increased above $5 \%$.
This was believed [28] to reflect the ability of gold to catalyse the oxidation of $\mathrm{NO}$ to $\mathrm{NO}_{2}$, followed by the reduction of $\mathrm{NO}_{2}$ to $\mathrm{N}_{2}$ by the hydrocarbon (in contrast to the ostensibly less favourable one-step reduction of $\mathrm{NO}$ to $\mathrm{N}_{2}$ which requires higher temperatures). In support of this, it was found that the admixture of $\mathrm{Mn}_{2} \mathrm{O}_{3}$ (an excellent catalyst for the $\mathrm{NO}+1 / 2 \mathrm{O}_{2} \rightarrow \mathrm{NO}_{2}$ reaction) to the gold-based catalyst mix was highly beneficial, with such catalysts able to compete with the best of the existing PGM-based catalysts in terms of activity, and surpassing them in terms of ability to tolerate moisture [28].

\subsection{Diverse other possibilities}

A more comprehensive list of the reactions that have been successfully catalysed by gold nano-particles may be found elsewhere, e.g. Thompson [6,9]. However it may be worth mentioning here that gold has efficacy for the following reactions which stand out as being of possible future importance: the hydrogenation of $\mathrm{CO}$ and $\mathrm{CO}_{2}$ to produce methanol, the hydrogenation or selective hydrogenation of unsaturated hydrocarbons (alkenes), the hydrochlorination of ethyne (acetylene) [4], the production of vinyl acetate monomer, and the liquid phase oxidation of ethane-1,2-diol [10].

\subsection{De-activation of gold catalysts}

Many catalysts undergo some form of deactivation during use and unfortunately, gold is no exception.

Sulphur and phosphorus are two of the few elements with a strong affinity for metallic gold. Therefore, it is expected that the activity of gold-based catalysts will be readily poisoned in gas streams containing these elements, particularly if they are in non-oxidised compounds. However, little information is available yet in the literature on, for example, $\mathrm{H}_{2} \mathrm{~S}$, a very likely contaminant of many possible process streams. There has been a study on the effect of $\mathrm{SO}_{2}$ and it was found [29] to poison $\mathrm{Au} / \mathrm{TiO}_{2}$ quite rapidly but not to have a deleterious effect on $\mathrm{Pt} / \mathrm{TiO}_{2}$. On the other hand, it has been claimed that Au-containing catalysts are far more resistant to deactivation in liquid phase reactions than their PGM counter-parts [10], implying that they may be more resistant to poisoning in other instances. The halogens also have a strong affinity for gold, and chloride is now known to be a potent poison of gold catalysts $[11,12]$. In this case the poison is more likely to occur during catalyst manufacture than in service, and would be caused, for example, by the use of $\mathrm{HAuCl}_{4}$ as a starting material.

There is also the possibility that deactivation of the gold nano-particles may occur by a combination of sintering and Oswald ripening. The net effect of these processes is an increased particle size and a reduced specific surface area. Both processes require temperatures of the order of 0.4 of the melting point, $\mathrm{T}_{\mathrm{m}}$, in order to proceed at reasonable rates, and since the melting point of bulk gold is $1068{ }^{\circ} \mathrm{C}$, they would 
ostensibly not occur at typical operating temperatures. However, three factors can exacerbate the problem. The first is that the melting point of gold nano-particles will be substantially reduced compared to the bulk element (see later), the second is that the local heat of reaction will raise the temperature of the nano-particles above that of the catalyst chamber and substrate, and the third is that chloride, a common residual impurity, appears to facilitate the sintering process [12]. The combination of factors may explain observed reactionassisted coarsening of nano-particles observed [7], even at $300 \mathrm{~K}$. However, it has been shown [7] that sintering is retarded when the gold is held on rough surfaces, implying that some control can be exercised over this problem.

Another mechanism for the de-activation of catalysts involves the deposition of carbon or graphite onto their surfaces (a problem sometimes known as 'coking'). This is certainly observed for the gold-catalysed hydrochlorination of ethyne [9] and is a general problem with all manner of catalysts, especially in the elevated temperature processing of hydrocarbons. Curiously, it has been reported that the addition of $\mathrm{Au}$ to at least one catalyst system retards or even eliminates the coking problem [30].

Finally, any gold-based catalysts that require the presence of oxidised $\mathrm{Au}$, such as $\mathrm{Au}^{3+}$, can be deactivated by the reduction of it to $\mathrm{Au}^{0}$. Reversal of the deactivation is not easy due to the difficulty inherent in oxidising $\mathrm{Au}$. A similar deactivation of the catalysts occurs if the support oxide is reduced to metallic form. For example, this happens if $\mathrm{Au} / \mathrm{Co}_{2} \mathrm{O}_{3}$ or $\mathrm{Au} / \mathrm{NiO}$ is used to catalyse the WGS reaction at elevated temperatures, and the result is a rapid deactivation of the catalyst system [14].

\section{INTRINSIC PROPERTIES OF GOLD NANO-PARTICLES}

\subsection{Crystal structure and morphology}

In the bulk form gold has the face centred cubic (fcc) structure which is closest-packed. Naturally-occurring macro-crystals of native gold exhibit the highly symmetrical cubic, octahedral or rhombododecahedral crystal forms associated with this crystal structure [31]. However, there is debate and even confusion in the literature regarding the structure and external form of nano-particles of gold [32], arising no doubt from the difficulties inherent in trying to physically characterise such tiny objects. As a result, several attempts have been made to predict the structure of gold nanoparticles using molecular dynamics or other calculations. However, there is not yet complete agreement between the results of the calculations and of the experimental measurements, with conflicting claims being made for icosahedral or decahedral quasi- crystal structures, amorphous structures, or octahedra, cuboctahedra and truncated octahedra based on fcc packing.

The icosahedral and decahedral clusters have five-fold symmetry, and for nano-scale particles the icosahedron in particular appears to yield an efficient compromise between surface area and packing density, whereas certain decahedra (an example of which is the Marks decahedron) have re-entrant facets, and are said to offer a compromise between surface area and strain energy [32]. Icosahedral clusters have a theoretical packing density of $68.8 \%$ in contrast to the $74.0 \%$ of the fcc structure [33]. Examples of the three shapes mentioned are given in Figure 1. Perfect icosahedral shapes are attained only for certain special numbers ('magic numbers') of atoms, a series, which starts 13, 55, 147, 309, 561, $923 \ldots$ atoms [33,34]. However, other 'stable' non-crystalline configurations besides icosahedra are possible, and they include low symmetry clusters based on 38 to 55 atoms [35,36] and Marks decahedra, based on 75, 77, 101 and 146 atoms [32,37]. Some groups, e.g. Cleveland et al. [32] have grouped all of the above non-crystallographic structures together as 'decahedral'. However, there is a continuum of possible atomic arrangements that extends from these 'icosahedral' or 'decahedral' structures through to ones of such low symmetry as to be effectively amorphous (e.g. refs. [35,36,38]). Some theoretical studies have concluded that it is these, practically amorphous, clusters that are most stable [36]. Most authors agree that the energies of all these configurations are so similar that they become very hard to differentiate $[35,36,38]$. Of course, the results of the calculations depend on assumptions regarding the nature of the inter-atomic interactions, e.g. their range [38] and how they are modified for surface atoms [36], and some use empirical parameters derived from fitting models to bulk gold [37], so the results should be treated with some caution. For example, it is apparently the models based on pair potentials that tend to predict that $\mathrm{Au}_{38}$ will be a truncated octahedron, whereas those using the more 'metallic' n-body potentials will predict that this will be amorphous [36]. For $35<n<500$ at least, it appears that various truncated octahedra should be more stable than icosahedra and cuboctahedra [32], although their stability would nevertheless not quite match that of Marks decahedra based on $\mathrm{Au}_{75}, \mathrm{Au}_{101}$ and $\mathrm{Au}_{146}$, which would tend to dominate any actual experimental particle dispersion [32].

Perfect cuboctahedral clusters with fcc packing can be assembled from the same series of magic numbers as for the icosahedra [33], and there are other perfect fcc clusters with octahedral or truncated octahedral crystal forms but different special numbers. These latter clusters include [35,39] a version of $\mathrm{Au}_{38}$, and $\mathrm{Au}_{116}$, $\mathrm{Au}_{140}, \mathrm{Au}_{225}, \mathrm{Au}_{314}$ and $\mathrm{Au}_{459}$. 


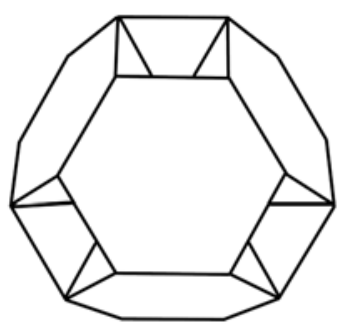

a

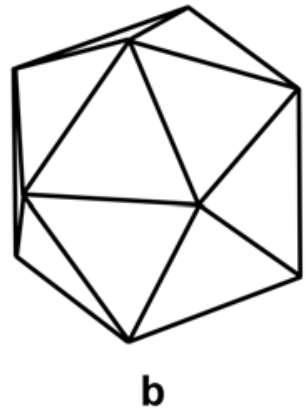

b

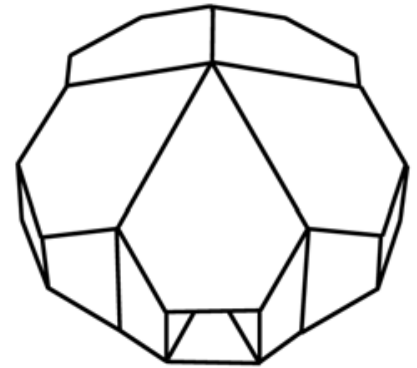

C

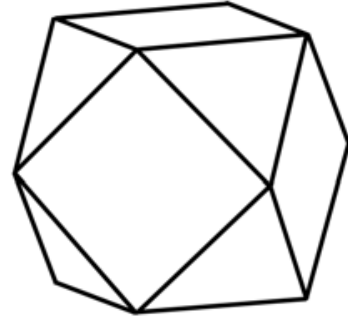

d

Figure 1. Comparison of (a) truncated octahedron, (b) icosahedron, (c) Marks decahedron and (d) cuboctahedron. Note the re-entrant facets in the truncated octahedron and the Marks decahedron. ((a) and (c) redrawn from Doye [50], $b$ and $d$ redrawn from Mackay [33]).

The fcc-based clusters generally present to the environment via a combination of crystal facets of the $\{111\}$ and $\{100\}$ types whereas the icosahedral ones are bounded by weak facets comprised of loosely packed, nominally $\{111\}$ surfaces. Some difference in surface properties might be expected as a result. In the case of gold it is said that very few of any of these clusters (whether decahedral or octahedral) are defectfree in practice and they will contain a high density of defects such as twins and stacking faults $[25,36,37,40,41]$.

As far as experimental evidence of cluster structure is concerned, it appears that in clusters passivated by alkythiolates at least, the most common schemes appear to be the Marks decahedron and the truncated octahedron [32,37,39] while in citrate sols the usual form is said to be a five-sided icosahedron or, more rarely, a plate [41]. Icosahedra of a nominal $\mathrm{Au}_{13}$ stoichiometry are also the active particle in $\mathrm{Au} / \mathrm{MgO}$ but in $\mathrm{Au} / \mathrm{TiO}_{2}$ it is the larger hemispherical fcc cuboctahedral ones that do the work $[25,26]$. Interestingly, it has been claimed that the gradual loss of catalytic activity that occurs in $\mathrm{Au} / \mathrm{MgO}$ over a period of several weeks is associated with the coarsening of the very small $\mathrm{Au}_{13}$ icosahedral particles $(<1 \mathrm{~nm})$ into truncated octahedra [26].

The many discrepancies with and between calculations and experiments have not yet been resolved. One possibility to be considered is that the presence of the passivating layer (which is inevitably ignored in calculations but present on most real clusters) stabilises the more ordered octahedral or decahedral crystal forms by virtue of reducing the difference in surface energy between them and the icosahedral or amorphous forms. Alternatively and less probably, perhaps the layer of passivating molecules makes little difference (e.g. as claimed by Liu [37]) and the calculations themselves are in error. Certainly, Wallenberg et al., who examined supposedly cuboctahedral (i.e. fcc) $\mathrm{Au}_{55}$ clusters in a TEM, were unable to find evidence for the passivating layer and assumed that it had evaporated in the vacuum [40] while X-ray diffraction of passivated clusters in this size range has shown [32] the dominance of Marks decahedra based on $\mathrm{Au}_{75}, \mathrm{Au}_{101}$ and $\mathrm{Au}_{146}$. Clearly there is no consensus on this topic, and it is likely that real clusters, even of a given size, are in any event likely to display a range of external morphologies and internal structures [37,38].

There are further complications relating to temperature, with the cuboctahedron form (at least for $140<n<310$ ) predicted [37] to transform to the icosahedral form at about $150^{\circ} \mathrm{C}$, en route to finally melting. Finally, the fcc lattice, with its associated cuboctohedral form, will always become the stable form above some limiting cluster size anyway, the magnitude of which is uncertain, with sizes of between $1 \mathrm{~nm}$ (corresponding to about 30 atoms in a sphere), 250 atoms ( $\sim 2 \mathrm{~nm})$ and $3 \mathrm{~nm}$ ( about 800 atoms) being given as representative cross-over values [7,26,32,34]. However, what is certain is that the bulk metallic state is completely established by $\mathrm{Au}_{40000}$, which has a diameter of about $11 \mathrm{~nm}$.

The cluster $\mathrm{Au}_{13}$ represents the smallest member of the theoretical sequence of icosahedral clusters. The average coordination number of atoms in $\mathrm{Au}_{13}$ cluster with an ideal cub-octahedral morphology would have been 5.5, and that of the atoms in the ideal $\mathrm{Au}_{13}$ icosahedron is 6.5 , but recent calculations suggest that the actual stable state for $\mathrm{Au}_{13}$ might have an average coordination number of 5.1, implying a lower degree of symmetry than exists in either fcc lattices or the ideal icosahedron [42]. Clusters of less than 13 atoms are too small for the concept of 'packing' to have much value, and they are sometimes termed 'molecular structures' in order to differentiate them from true clusters [32].

Knowing that these clusters are nominally closepacked, and allowing for a packing density of $70 \%$ (which is intermediate between that of body-centred 
cubic and closest-packed structures), it may be shown that

$$
\left(\frac{d_{\text {cluster }}}{2}\right)^{3} \approx n \cdot r_{A u}^{3} \cdot \frac{1}{0.70}
$$

which simplifies to

$$
\left(d_{\text {cluster }}\right)^{3} \approx 0.0342 n
$$

where $d_{\text {cluster }}$ is the diameter in $\mathrm{nm}$ of a nominally spherical cluster filled with $n \mathrm{Au}$ atoms of radius $r_{\mathrm{Au}}$ at $70 \%$ packing efficiency. The approximate diameter of spherical and hemispherical clusters of varying numbers of atoms are shown in Figure 2. From this it is evident that an $\mathrm{Au}_{38}$ cluster is very small, with a diameter of only about $1.0 \mathrm{~nm}$, while $\mathrm{Au}_{75}$ has a diameter of about $1.4 \mathrm{~nm}$. The literature generally attributes catalytic activity to gold clusters of up to 5 $\mathrm{nm}$ diameter, which would correspond to about $\mathrm{Au}_{3600}$ if spherical and $\mathrm{Au}_{1800}$ if hemispherical, while for 3 $\mathrm{nm}$ particles, which are often cited as being particularly active, the corresponding hemispherical clusters contain about 400 atoms.

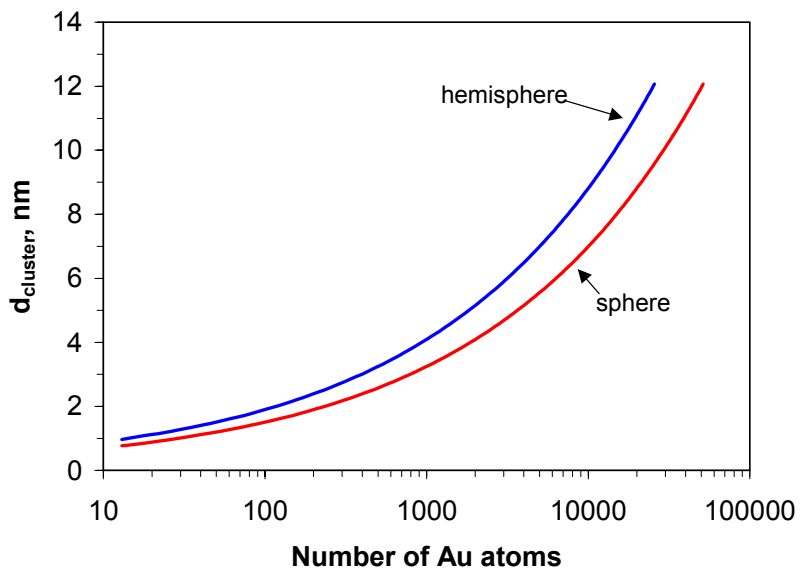

Figure 2. Approximate size of nominally spherical and hemispherical clusters of $A u_{n}$.

The attachment of gold clusters to a substrate provides new geometric possibilities besides the merely hemispherical. For example, it has been shown that 2 $\mathrm{nm}$ diameter clusters consisting of two layers of about $50 \mathrm{Au}$ atoms each are active for CO oxidation [7]. Such a structure is too thin to have fcc or hep structure, and is basically two-dimensional. Given that all experimental preparations of gold nano-particles have a distribution of sizes which is often quite broad, it is not always clear whether all or perhaps only a few of the particles are responsible for the catalytic activity. In one rather extreme interpretation, the equiaxed crystalline gold clusters forming the top end of the size distribution would not contribute at all to the catalytic activity of a sample, and instead the activity would be due only to that part of the distribution of shapes and sizes that is very small, and perhaps two-dimensional in nature! This could explain the high activity of certain samples of $\mathrm{Au}(\mathrm{OH})_{3}$ which are ostensibly nonmetallic, lacking visible equiaxed clusters and yet may be very active (e.g. Hodge et al [20]). In this scenario the substance contains two-dimensional sheets of $\mathrm{Au}$ atoms which are catalytically active but scarcely discernible, and which are therefore overlooked by conventional electron microscopy. However, good catalytic activity has also been obtained from 'model catalysts', made by combining equiaxed gold colloid particles of known size distribution, with a support such as $\mathrm{TiO}_{2}$ (e.g. Tanaka et al. [26]), which weakens this hypothesis.

\subsection{Electronic structure}

The electronic structure of gold in the bulk form is of course metallic, and may be given as $[\mathrm{Xe}] 4 \mathrm{f}^{14} 5 \mathrm{~d}^{10} 6 \mathrm{~s}^{1}$, although the $6 \mathrm{~s}^{1}$ electron is not readily ionizable and gold is the most electronegative of all metals [43]. However, very recently, a number of elegant studies have shown how nano-particles of gold lose their metallic nature as their size decreases, the transition occurring at a size dependent on the chemical environment but, as mentioned previously, certainly somewhere between 1 and $3 \mathrm{~nm}$ [7,34], corresponding to a hemispherical cluster with somewhere between about 14 and 140 atoms. The special electronic configuration of very small nano-particles results from the fact that their physical dimensions are smaller than the characteristic dimension of the electron wave function of the bulk material. As far as the authors are aware, the 'electronegativity' of such clusters has not been determined.

Catalytic activities of the two-atom layer 'clusters' referred to in the previous section are found to be exceedingly size dependent, peaking for example at a cluster diameter of close to $3 \mathrm{~nm}$, and falling precipitously within $0.5 \mathrm{~nm}$ either side. This size range was associated with the presence of a band gap of particular magnitude in the cluster [7], in contrast to bulk gold which has no band gap at all. The band gap of $\mathrm{Au}$ discs smaller than $2 \mathrm{~nm}$ increased further but their activity was low. This work suggests very strongly indeed that, for Au clusters on some supports at least, peak catalytic activity is associated with a special transitional electronic structure with particular semi-conductor characteristics. It should be noted that gold is not unique in this respect, and that other noble metals, such as Pd and Pt, have also shown similar results $[7,34]$. However, it is obvious that, for reasons of oxygen affinity, only $\mathrm{Au}$ and $\mathrm{Pt}$ will be able to form stable metallic nano-clusters at atmospheric values of $p_{\mathrm{O}_{2}}$. All other metals will normally be oxidised in this size range.

The electronic configuration of a spherical metal cluster has been quite successfully described by a somewhat simplified spherical shell model [34]. In this scheme the valence electrons of the atoms of a cluster 
are 'placed' into a spherically symmetrical energy well, and allowed to distribute themselves according to the usual principles. Since each individual gold atom has one valence electron", a cluster of $\mathrm{Au}_{19}$, for example will have an electronic configuration of $\left(1 \mathrm{~s}^{2} 1 \mathrm{p}^{6} 1 \mathrm{~d}^{10}\right) 2 \mathrm{~s}^{1}$ and is obviously more reactive than say, $\mathrm{Au}_{18}$, which has a configuration of $\left(1 \mathrm{~s}^{2} 1 \mathrm{p}^{6} 1 \mathrm{~d}^{10}\right)$, with filled shells $[8,44]$. Note that this notation expresses the collective structure of the cluster's accumulation of the delocalised valence electrons only, and should not be confused with that of the individual $\mathrm{Au}$ sub-valence electrons, which will reside in a somewhat shielded electronic structure of their own. Imparting a negative charge to the cluster will add a new electron, and would convert an unreactive $\mathrm{Au}_{18}{ }^{0}$ cluster to a more reactive $\mathrm{Au}_{18}$ form with the $\left(1 \mathrm{~s}^{2} 1 \mathrm{p}^{6} 1 \mathrm{~d}^{10}\right) 2 \mathrm{~s}^{1}$ structure [8]. Of course, if the cluster is not actually spherical then this model will be less appropriate because the electronic configuration will be significantly more complex. Another problem with the model is that in reality the cluster might be more realistically described as acquiring only a fractional electronic charge $[44,45]$, e.g. $1 / 2$ e, because of an overlap between the electron distribution of the oxide support, for example, and the cluster. Also, it is not clear how useful this model is in terms of predicting the band gap of metallic nanoparticles, nor does the crystal structure of the cluster come into it. The crystal structure ought to affect the electronic structure, with less symmetrical structures calculated [38] to have simpler, but still metallic, density of states (DOS). Nevertheless, not withstanding these problems, the shell model enjoys an encouraging measure of predictive success, as will be shown shortly.

\subsection{Melting point}

The physical properties of nano-particles are expected to deviate from those of the bulk metal, both on account of their vastly increased ratio of surface atoms to internal ones and of course as the result of their different electronic structure. Several theoretical and experimental forays into the problem of calculating the melting point of unsupported (i.e. 'naked') gold nanoparticles have now been made $[37,46-48]$ and in general a pronounced reduction in the melting point with reduction in particle (or wire) diameter has been predicted.

The general form of the depression in melting point was worked out as early as 1909 , but, after some modification by later workers, a useful version of it is

\footnotetext{
* The number of valence electrons for gold may also be taken as 11 (e.g. Mills [44]), in which case the electronic configuration of the cluster according to the rather simplified spherical model will be quite different. However, the principle that clusters with odd numbers of electrons will be more reactive towards oxygen will still hold [44] for the same values of $n$ in $\mathrm{Au}_{n}{ }^{-}$and $\mathrm{Au}_{\mathrm{n}}{ }^{0}$.
}

$$
\frac{T_{m}(r)}{T_{m}(\infty)}=1-\frac{4}{\rho_{s} L}\left\{\gamma_{s}-\gamma_{l}\left(\frac{\rho_{s}}{\rho_{l}}\right)^{2 / 3}\right\} \frac{1}{d}
$$

[48] where $T_{\mathrm{m}}(r)$ and $T_{\mathrm{m}}(\infty)$ are the melting points of particle of radius $r$ and the bulk material respectively, $\rho_{\mathrm{s}}$ and $\rho_{\mathrm{l}}$ are the density of solid and liquid respectively, and $\gamma_{\mathrm{s}}$ and $\gamma_{1}$ are the surface free energy of the solid and liquid.

Alternatively, the depression in melting point may just be empirically expressed as [47]

$T_{\mathrm{m}}(r)=T_{\mathrm{m}}(\infty)-\mathrm{C} / r$

where $\mathrm{C}$ is a constant.

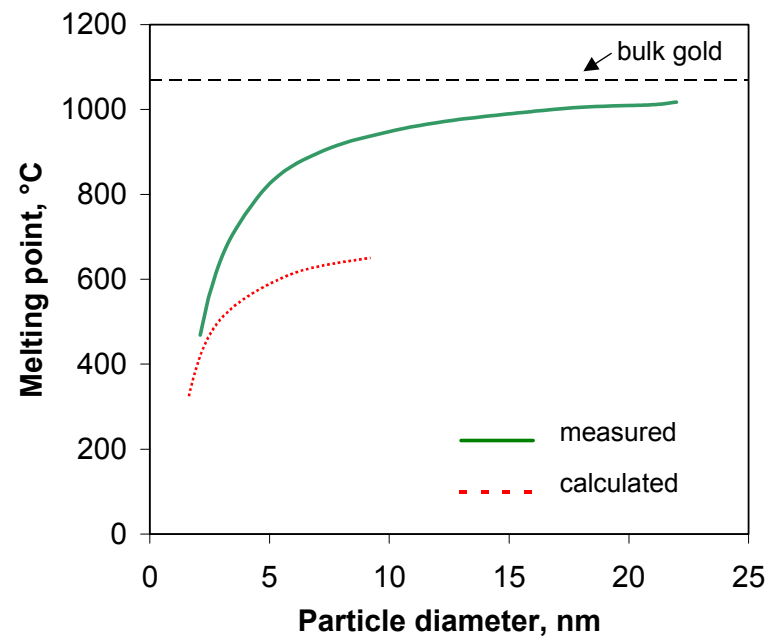

Figure 3. Reduction of melting point with a decrease in size of gold nano-particles, showing both theoretical data computed using molecular dynamics [37] and measured data derived from gold nanoparticles encapsulated in silica [48].

The results of two studies for particles are shown in Figure 3. The details differ considerably, but even taken conservatively, these calculations indicate that catalytically active gold particles in the $5 \mathrm{~nm}$ size range $\left(\sim \mathrm{Au}_{3600}\right)$ would be molten at about $830^{\circ} \mathrm{C}$, particles of about $2 \mathrm{~nm}$ (about $\mathrm{Au}_{200}$ ) would liquefy at $350^{\circ} \mathrm{C}$ and, by extrapolation, particles of about $1 \mathrm{~nm}\left(\sim \mathrm{Au}_{30}\right)$ at $200{ }^{\circ} \mathrm{C}$. The depression in melting point becomes pronounced for $\mathrm{Au}_{n}$ where $n<2000$, corresponding to a nominal particle size of $\sim 4 \mathrm{~nm}$. Given that gold catalysts have been observed to be active at up to $500^{\circ} \mathrm{C}$ and that this is said to be the work of particles in the 2 to $5 \mathrm{~nm}$ size range, this implies either that in some cases the nano-particles are active in the liquid phase, or that the calculations are misleading. One factor not taken into account in the calculations is the effect of the oxide, or other, support. 
Computer simulations of the melting of particles suggest that it starts at the surface and proceeds inwards over a wide range of temperature [37] to produce quite a broad indication of melting, unlike the case for the bulk metal, which of course melts quite suddenly if pure. However, Dick et al. [48] had no difficulty experimentally determining the melting point of particles in the 1.5 to $20 \mathrm{~nm}$ size range using differential thermal analysis (DTA), and ascribed the broadening of the melting endotherms in their experiments to a dispersion in particle sizes, not to any inherent material property of nano-scale particles. Also, they had encapsulated their gold particles in a silica shell, implying that in this case the presence of a 'support' did not prevent the depression in melting point. Taken collectively, these results support the claim (e.g. Poizot [49]) that even oxide-supported gold nano-particles of $1 \mathrm{~nm}$ diameter or smaller would be molten at $200^{\circ} \mathrm{C}$, a factor which would have some implications on the mechanism of catalysis. Further experimental work is needed to clear up these issues.

An indirect implication of the above phenomena is that the rate of self-diffusion in clusters rises sharply as their size falls [48]. This means that, for example, bimetallic clusters will interdiffuse rapidly at surprisingly low temperatures. Also, the Tammann temperature, which is the temperature at which the particles begin to sinter significantly, will be greatly reduced as the particle size decreases.

\section{MECHANISMS OF CATALYSIS}

\subsection{Active-perimeter models}

The pioneering work by M. Haruta [3] showed that activity in gold catalysts could be associated with hemispherical particles of $\mathrm{Au}^{0}$ with diameters of less than about $5 \mathrm{~nm}$, which are attached to oxide supports. $\mathrm{He}$, and several subsequent workers have concluded $[18,51]$ that it was the perimeter of the hemisphere which was the active site, at least for the $\mathrm{CO}$ oxidation reaction. This explanation is currently the most generally accepted one in the literature for catalysis by gold nano-particles, although there are differences on details.

For the sake of a simplified analysis let the catalyst particles be represented by a hemisphere of radius $r$, attached to a substrate. If the conversion of reactant is proportional to the length of the perimeter, then it can be shown that the conversion, $C_{\text {reaction, }}$ per gram of gold is proportional to

$$
C_{\text {reaction }} \propto \frac{1}{r^{2}}
$$

In this model, the activity of the perimeter atoms of the gold cluster may be in a special state controlled by electronic interactions with the oxide substrate. In general, one of the reacting species, e.g. $\mathrm{O}_{2}$ would adsorb either at the perimeter site itself or on the oxide support, and the other, e.g. $\mathrm{CO}$, on the gold nanoparticle, with the reaction between the two species occurring at the perimeter to produce $\mathrm{CO}_{2}$. Either way, the nature of the support would control the reaction of $\mathrm{O}_{2}$ and $\mathrm{CO}$ along the perimeter. There is certainly considerable evidence in support of the claim that the chemical identity of the support is important, and for example it has been shown that different activities are obtained for different supports, even if the Au particle size is unchanged [17]. However, for activity to occur, the gold nano-particles must be properly attached to the support too. There is also evidence to support this and, for example, the beneficial effect of calcination in converting inert colloidal $\mathrm{Au}$ plus $\mathrm{TiO}_{2}$ composites into active $\mathrm{Au} / \mathrm{TiO}_{2}$ catalysts has been interpreted in terms of the interaction of the discrete colloidal particles with the substrate during calcination, and the associated formation of an attachment perimeter [26]. Conversely, Grisel et al. [21], have shown how the addition of a little $\mathrm{MnO}_{\mathrm{x}}$ to an $\mathrm{Au} / \mathrm{Al}_{2} \mathrm{O}_{3}$ system was able to stimulate a significant improvement in $\mathrm{CO}$ oxidation, allegedly by changing the properties of the perimeter without changing the Au particle size or characteristics.

As mentioned, there is disagreement amongst the supporters of this model concerning whether the $\mathrm{O}_{2}$ is adsorbed on the perimeter itself or the nearby oxide support. For example, Grisel et al. [21], Bond [1,18], Schubert [5] and Haruta [51] have opted for the transition metal oxide collecting and disassociating the $\mathrm{O}_{2}$, (especially at surface anion vacancies or ' $\mathrm{F}$ centres') while Sanchez et al. [45] have shown by calculation that $\mathrm{O}_{2}$ should absorb as $\mathrm{O}_{2}^{-}$onto gold atoms along the interface perimeter of, for example $\mathrm{Au}_{8}$ on $\mathrm{MgO}$.

Even if the $\mathrm{O}_{2}$ is adsorbed onto the oxide support, the perimeter might still enjoy a special role. Bond \& Thompson [18], for example, have proposed that the gold nano-particle is attached to the oxide support via an intermediate layer of $\mathrm{Au}^{x+}$ atoms, and the oxidised state of these atoms is essential for catalytic ability. Supporting evidence has come from Mössbauer studies, which have shown $[19,26]$ that the most active catalysts (in metal hydroxide-supported systems at least) have the highest fraction of $\mathrm{Au}^{+}$, while EXAFS analysis of $\mathrm{Au} / \gamma-\mathrm{Al}_{2} \mathrm{O}_{3}$ prepared by depositing $\mathrm{AuCl}_{3}$ onto $\gamma-\mathrm{Al}_{2} \mathrm{O}_{3}$ indicated that activity for $\mathrm{CO}$ oxidation requires a polymeric $\mathrm{Au}(\mathrm{OH})_{3}$ precipitate [52]. In this case the presence of $\mathrm{Au}-(\mathrm{O})-\mathrm{Au}$ was beneficial while that of $\mathrm{Au}-(\mathrm{O})-\mathrm{Al}$ was not.

On the other hand, studies by Haruta's group found that $\mathrm{Au}^{+}$played no role in the activity of $\mathrm{Au} / \mathrm{TiO}_{2}$, with maximum activity only occurring once all $\mathrm{Au}^{{ }^{x+}}$ had been reduced to $\mathrm{Au}^{0}$ by calcination [26]. In yet another complication, the beneficial role of humidity has been explained [18] as being the result of hydroxyl ion 
adsorbed along the perimeter, and serving there as an intermediary in the reaction between $\mathrm{O}_{2}$ and $\mathrm{CO}_{2}$.

If the active-perimeter model were true then the crystal structure of the catalytic gold particles should not be particularly important. The fact that both icosahedral and cuboctahedral particle are catalytically active (but perhaps on different supports) has been advanced as evidence in support of the active-perimeter model [26].

\subsection{Active-particle ('electronic') model}

The oxidation of $\mathrm{CO}$ on a heterogeneous gold catalyst evidently requires that at least one molecule each of carbon monoxide and oxygen come into contact with one another on the surface of the gold nano-particle. Both gases have a negligible affinity for bulk gold surfaces $[1,7,8]$, at least for temperatures above $150 \mathrm{~K}$ [5] thereby explaining the absence of catalytic activity for this reaction on bulk gold. However, very small nano-particles are obviously different and direct evidence that both oxygen and carbon monoxide can adsorb on neutral [42] or negatively-charged [8] gold nano-particles is available. In particular, Whetten and co-workers at Georgia Institute of Technology have showed [8] that $\mathrm{O}_{2}$ bonds readily with $\mathrm{Au}_{n}{ }^{-}$(provided $n$ is even and $n \neq 16$ ), with the oxygen attaching as a superoxide $\left(\mathrm{O}_{2}{ }^{-}\right)$. No oxide support was involved in these experiments, and catalytic activity for $\mathrm{CO}$ oxidation was shown by a naked gold particle suspended in a gas stream. This has led to an alternate hypothesis to explain catalysis by gold nano-particles, in terms of which the catalytic activity occurs on the surface of a cluster, and arises from a special electronic configuration of it. In this mechanism the role of the support is simply to modulate the electronic structure of the cluster.

One issue to consider is whether it is, for example, both $\mathrm{O}_{2}$ and $\mathrm{CO}$ that are co-adsorbed onto the catalyst system, where they subsequently react (the LangmuirHinshelwood reaction pathway [45]) or whether only one of the reacting species adsorbs, with the other coming into contact with it by kinetic collision from the gas phase (the Eley-Rideal reaction pathway [45]). However, current opinion is for the former [5].

Interestingly, it has been shown that catalytically active gold results if $\mathrm{Au}$ clusters are deposited onto F-centre (oxygen-vacancy) sites on $\mathrm{MgO}$ but not if the F-centres were absent [42,45]. This observation may be interpreted as support for either the active-perimeter or the active- particle hypotheses. If we accept the activeparticle model then we would suppose that the excess electron density at the F-centre site is transferred to the cluster and onward to the adsorbed $\mathrm{O}_{2}$ to form the superoxide needed for the catalytic reaction. Further indirect evidence in support of this may be drawn from the work of Valden et al [7] who observed that the catalytic activity of the gold was reduced or absent if it was placed onto a stoichiometric (i.e. fully oxidised) surface of $\mathrm{TiO}_{2}$. Such a fully oxidised surface will have very few F-centres and therefore, the gold clusters on it would not be negatively charged and hence not able to react with $\mathrm{O}_{2}$ to form superoxide. Of course, supporters of the active-perimeter model, who included Valden et al., would say that the difference is that an oxide without F-centres is not able to adsorb $\mathrm{O}_{2}$ and therefore unable to supply it to the active perimeter sites. In this view, it is the supply of adsorbed $\mathrm{O}_{2}^{-}$that is rate limiting, and the reaction can be considerably expedited if $\mathrm{O}_{2}^{-}$can be supplied from the substrate rather than on the nano-particle itself [5].

In a completely opposite view of the issue, Japanese workers ${ }^{26}$ have claimed that gold nano-particles of $<2$ $\mathrm{nm}$ diameter become catalytically active by transferring electronic charge to the $\mathrm{TiO}_{2}$ substrate. The $\mathrm{Au}_{n}{ }^{\delta+}$ clusters then apparently acquire the ability to dissociate $\mathrm{H}_{2}$, for example.

The adsorption of $\mathrm{O}_{2}$ onto clusters can also be correlated to the electronic configuration of the cluster, which was discussed earlier. In this case, charge and crystal structure is apparently not as important, and what counts is that there should be a single electron in the valence shell of the cluster. This hypothesis has been supported by detailed $a b$ initio calculations [44]. The electronic configurations of $\mathrm{Au}_{18}{ }^{-}$and $\mathrm{Au}_{20}{ }^{-}$, both of which react strongly with $\mathrm{O}_{2}$, and which contain 19 and 21 electrons respectively, may be written in terms of the simple shell model introduced earlier as $\left(1 \mathrm{~s}^{2} 1 \mathrm{p}^{6} 1 \mathrm{~d}^{10}\right) 2 \mathrm{~s}^{1}$ and $\left(1 \mathrm{~s}^{2} 1 \mathrm{p}^{6} 1 \mathrm{~d}^{10}\right) 2 \mathrm{~s}^{2} 1 \mathrm{f}^{1}$ respectively [8]. By donating an electron to $\mathrm{O}_{2}$ to form $\mathrm{O}_{2}^{-}$, the cluster's electronic configuration assumes a closed shell form with an associated energetic advantage. According to this hypothesis $\mathrm{Au}_{19}{ }^{0}$ and $\mathrm{Au}_{21}{ }^{0}$ would also be reactive since they ought to have the same shell electronic configuration with an unpaired electron. Unfortunately the available experimental data and $a b$ initio calculations for neutral clusters are in conflict, with calculations supporting this contention [44] and measurements in conflict with it [42]. However, note that $\mathrm{O}_{2}$ should in principle bond more strongly with negatively charged clusters than to neutral ones with the same number of electrons. The reason for this is that the ionisation potential of a negatively charged cluster should be lower than that of a neutral one.

Heiz et al. [42] observed that $\mathrm{Au}_{8}$ was far more reactive than $\mathrm{Au}_{13}$, an observation ostensibly at odds with the spherical shell model described previously, until it is noted that they only obtained activity for $\mathrm{Au}$ clusters when they were present on defect-rich $\mathrm{MgO}$ substrates. Once again, one possible explanation for the discrepancy is that the extra electron density from the F-centres of such substrates was taken up into the cluster to provide a reactive $\mathrm{Au}_{8}{ }^{-}$cluster with a $\left(1 \mathrm{~s}^{2} 1 \mathrm{p}^{6}\right) 2 \mathrm{~s}^{1}$ configuration and an unpaired electron.

If indeed only one oxygen molecule can be absorbed per cluster at a time, then the acute size sensitivity of the catalytic activity of gold nano-particles can be readily explained. After dividing the number of 
particles with their mass, and simplifying, the activity can be shown to be

$$
C_{\text {reaction }} \propto \frac{1}{r^{3}}
$$

The issue of whether the adsorption of the $\mathrm{O}_{2}$ on gold is eventually dissociative or not also arises, with some authors ${ }^{7}$ claiming the adsorbed $\mathrm{O}_{2}$ goes on to form monatomic oxygen while others [8,21] disagree with this on the basis [8] that the formation of two oxide ions necessarily involves four electrons, a process considerably more complex and less probable on gold than the simple one electron scheme required to produce $\mathrm{O}_{2}^{-}$. However, the four electron process is known to occur with more active metal clusters, such as those of copper or sodium [7]. Certainly, calculations show that, the stronger the bond between $\mathrm{O}_{2}^{-}$and $\mathrm{Au}_{\mathrm{n}}$, the greater the $\mathrm{O}-\mathrm{O}$ distance in the superoxide [44], but this apparently does not occur to a sufficient extent in gold to dissociate the bond. It may be the unique characteristic of gold nano-clusters to form superoxide adsorbates rather than disassociated oxides that defines its unusual catalytic activity [8]. In an alternative but nearly equivalent view, it is the low bond strengths between $\mathrm{Au}$ and the reacting species that makes gold such an active catalystn [21].

\subsection{The geometric models}

If the surface of a material (or some site on the surface of the material) has a particular ability to catalyse a chemical reaction, then it follows that increasing the specific surface area (expressed as $\mathrm{m}^{2} / \mathrm{g}$ ) of the material will increase the activity of the catalyst. In this scheme the chemical identity of the catalyst support is completely unimportant; it exists solely to pin the catalytic particles and prevent them from sintering together.

After dividing the surface area of a particle by its mass, it can be shown that

$$
C_{\text {reaction }} \propto \frac{1}{r}
$$

The efficacy of the catalyst in terms of the three models is plotted in Figure 4 as a function of the hemisphere diameter, down to $1 \mathrm{~nm}$, considered here to be about as small as the trend could go. A hemisphere of $1 \mathrm{~nm}$ diameter would contain only about 15 atoms of gold, and anything smaller than that is probably no longer a 'hemisphere'. The data have been normalised in each case to yield a value of $2 \times 10^{-5}$ moles CO oxidised per gram Au per second at a particle size of 5 $\mathrm{nm}$, a representative figure for these catalysts.

When plotted in a linear scale (Figure 4a), it is evident that all three models produce a sharp increase in activity with decrease in particle size. Greater differentiation between the various models is visible when they are plotted on a logarithmic scale (Figure 4b).

Much of the increase in catalytic activity of other metals and materials may be explained entirely or substantially by the above geometric argument. However, in the case of gold, the explanation is controversial. This is because bulk gold apparently has no catalytic activity at all for reactions such as $\mathrm{CO}$ oxidation and, as mentioned, it has scarcely any ability to absorb $\mathrm{O}_{2}$ or $\mathrm{CO}$ (although the very active monatomic $\mathrm{O}$ will attach to it [21]). This is quite unlike the case [21] for Pt, upon which CO will readily absorb and which can split the $\mathrm{O}-\mathrm{O}$ bond in $\mathrm{O}_{2}$.

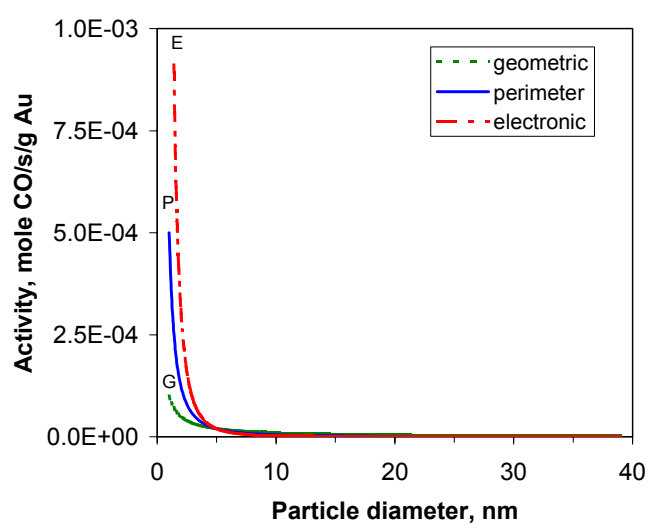

(a)

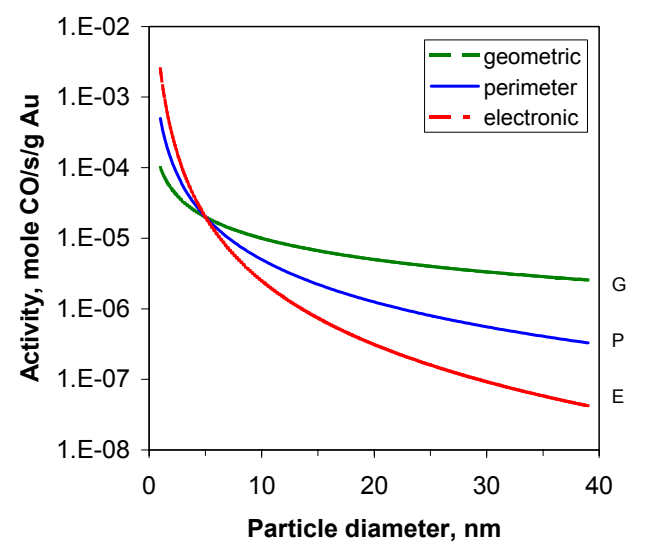

(b)

Figure 4. Dependence of catalyst activity on diameter of hemispherical catalyst particles, as a function of three different mechanisms. The curves have been normalised to a typical activity of $2 \times 10^{-5}$ moles CO/second/g Au at a particle size of $5 \mathrm{~nm}$, (a) linear, (b) logarithmic.

In a development of the geometric model, the activity of the surface is further determined by the density of specific surface sites. In this case the remarkable activity of gold nano-particles may be explained as being the result of a net increase in number of such 
special sites caused by the increase in the specific surface area. However, it is possible that gold clusters of equal size and ostensibly similar electronic configuration could exhibit very different reactivities, since it is actually their number of special surface sites above all else that determines their activity, and the surface density of the special sites is not necessarily the same for all forms of gold. It would be a neat conclusion to the confusion if, for example, icosahedral particles were active and cuboctahedral ones were not. However, the observation [25] that while icosahedral hemispherical clusters are associated with activity in $\mathrm{Au} / \mathrm{MgO}$, it is hemispherical fcc cuboctahedral ones that do the work in $\mathrm{Au} / \mathrm{TiO}_{2}$ is a strong counterargument. Unfortunately, this last observation can be interpreted as providing evidence for more than one mechanism: the simplified electronic structural theory presented in the previous section (since $a b$ initio quantum mechanical calculations have suggested that different cluster configurations possess only slightly different electronic configurations [38]), and the activeperimeter model (since, if the structure of the gold particle was unimportant, it must be the interaction with the support that differentiates catalysts).

However, some support for the idea of special surface sites has come from the work of Kung et al. [12], who studied how gold-based catalysts were affected by poisoning by $\mathrm{Cl}^{-}$. Their results indicated that the actual activity of the gold was due to an exceedingly small proportion of the surface gold atoms, about one in a thousand, implying that the reaction occurs at a few special sites only. What might such sites consist of ? Perhaps they merely have to be gold atoms of low coordination situated at steps or other defects, which have already been proposed to be considerably more electropositive (and therefore readily ionisable to $\mathrm{Au}^{x+}$ ) than normal gold atoms (e.g. Thompson and Bond [18]), or, according to Kung [12], they are regions of $\mathrm{Au}^{+} \mathrm{OH}^{-}$, embedded in a surface of more numerous $\mathrm{Au}^{0}$ atoms. Either way, this would be consistent with a significant amount of work $[18,19]$ that has found that high catalytic activity appears to be associated with gold atoms that are oxidised, either as $\mathrm{Au}^{1+}$, or $\mathrm{Au}^{3+}$, or perhaps $\mathrm{Au}^{\delta+}$, where $0<\delta<3$. How such an oxidised species could avoid being reduced to $\mathrm{Au}^{0}$ in an environment containing $\mathrm{CO}$ or $\mathrm{H}_{2}$ is not yet explained, and it is obvious that $\mathrm{a} \mathrm{Au}^{\delta+}$ site will certainly not be able to reduce $\mathrm{O}_{2}$ to $\mathrm{O}_{2}^{-}$(thereby placing this explanation at odds with any mechanism requiring superoxide formation).

\section{DISCUSSION}

\subsection{Future prospects for gold catalysts}

Gold has been demonstrated to be the best catalyst for at least three reactions of industrial importance so far. These are the hydrochlorination of ethyne (acetylene) to make vinyl chloride monomer, a possibility that was actively pursued [55] in the late $80 \mathrm{~s}$, the low temperature oxidation of carbon monoxide, and the production of vinyl acetate monomer from acetic acid, ethylene and oxygen. Commercial exploitation of the first reaction would in some instances displace a troublesome and toxic catalyst containing mercuric chloride but would of necessity need to compete with other means of producing vinyl chloride. However, world production of vinyl chloride continues to grow at about 5\% despite concerns about its toxicity, carcinogenicity and possible effect on the ozone layer, and there appears to be some merit in reconsidering gold for this role. With regard to the third reaction, gold-palladium catalysts were very successfully applied in 2001 at a new plant to make vinyl acetate monomer in the UK and the result is said to a saving of $30 \%$ in capital costs [56].

The opportunities to use Au-based catalysts for COremoval appear to arise from three factors. The first is the extraordinary activity of these catalysts at room temperature and below. This offers the prospect of removing low concentrations of $\mathrm{CO}, e . g$. from the air conditioning systems of buildings or vehicles, without any need to heat the catalyst bed using external means. This property might also be profitably employed to remove the first $\mathrm{CO}$ produced from a motor vehicle engine when it is started. Conventional catalysts require some time to reach their 'light off' temperatures, and the quantity of $\mathrm{CO}$ (and hydrocarbon fumes) emitted to the environment during this warm-up period is significant. Use of gold-based catalysts would allow for catalytic removal of $\mathrm{CO}$ from the instant the engine is started. The second property of interest is that the activity of some conventional catalyst systems, e.g. those based on hopcalite $\left(\mathrm{MnO}_{\mathrm{x}} \cdot \mathrm{CuO}_{\mathrm{y}}\right)$, is significantly prolonged by the incorporation of gold nano-particles. Ordinary hopcalite, which is used in respirators such as might for example be used by fire-fighting personal, deactivates after only an hour or so of use [9], which is obviously a critical safety issue. However, as mentioned previously, $\mathrm{Au} / \mathrm{MnO}_{\mathrm{x}} \cdot \mathrm{CuO}$ y catalysts retain their activity for days at a time. Finally, gold-based catalysts appear not to be deleteriously effected by humidity, and in fact appear in most cases to be enhanced by it $[8,9,18]$. This is unlike most of the existing competing catalyst systems.

However, the low melting point of gold, and especially of gold nano-particles, is a matter for concern, given that the exhaust gas streams of petrol engines, for example, can readily reach $800^{\circ} \mathrm{C}$. Clearly, any goldbased catalyst used in this application must be protected from being overheated, for example by cooling it with cold air, or by the action of a valve that diverts the hot exhaust away from the catalyst once the normal operating temperature of the exhaust has been reached.

Prospects for gold-based catalysts in remediating the fumes from diesel engines is better, not only because they operate at lower temperatures and generate 
exhaust gas streams of a nominal $500^{\circ} \mathrm{C}$, but also because the legislation and technology for removing pollutants from diesel exhausts is still in its infancy, thereby giving gold-catalysts a chance to get a foothold. In this respect it is the CO-oxidising powers of gold at low temperatures, its ability to catalyse the reduction of $\mathrm{NO}_{2}, e . g$. with entrained propene, and its tolerance to $\mathrm{H}_{2} \mathrm{O}$, that commends its use.

Another possible growth area for gold-based catalysts is in the production of hydrogen peroxide. Production of $\mathrm{H}_{2} \mathrm{O}_{2}$ is enjoying strong growth due the fact that it is now considered a more eco-friendly disinfectant and oxidant than the halogens. It has been claimed [9] that Au might form the basis for an excellent catalyst in this system due to its reluctance to dissociate $\mathrm{O}_{2}$. However, once again it would have to compete with established processes, for example the one using alkylhydroanthraquinone.

\subsection{Mechanism of catalysis}

It appears that there is no single mechanism of catalysis by gold. While it is evidently easier to obtain good activity on 'reducible' oxides, it is by no means excluded on so-called 'inert' supports [5]. It has been suggested that, for $\mathrm{Au}^{0}$-containing catalysts at least, the active-particle scenario applies to gold on 'inert' supports such as $\mathrm{MgO}, \mathrm{Al}_{2} \mathrm{O}_{3}$ or $\mathrm{ZrO}_{2}$, while the activeperimeter model applies for $\mathrm{Au}^{0}$ on 'reducible' oxides such as $\mathrm{Fe}_{2} \mathrm{O}_{3}, \mathrm{CoO}_{\mathrm{x}}$ and $\mathrm{TiO}_{2}$. If true then oxygen adsorption on the support is useful, but not essential. The observations that both naked nano-clusters [8] and gold powders [53] can be catalytically active further weakens any claim that an oxide support and the associated active-perimeter is an essential feature of the mechanism. However, the fact that both mesoporous gold sponges [54] and the larger gold nano-particles [11] can be active also destroys any claim that it is a unique semi-conducting electronic configuration that confers catalytic activity. This is because in these instances the metallic particles are either in electrical contact or are no longer strictly nano-scale, and so either way they must have the electronic configuration of the bulk material. However, the active-perimeter model can still be applied to mesoporous gold sponge, except that there has been a geometric inversion, and the catalyst now consists of oxide particles attached to a gold support via a common perimeter. This is because meso-porous gold sponges prepared by dealloying of intermetallic compounds inevitably contain a residual oxide impurity.

The high activity of $\mathrm{Au}(\mathrm{OH})_{3}$ reported by several groups $[19,20,26]$ implies that $\mathrm{Au}^{0}$ may not even be essential for catalysis to take place. Catalytic activity in $\mathrm{Au}(\mathrm{OH})_{3}$-based systems cannot be readily explained by either the active-perimeter or active-particle models, since $\mathrm{Au}^{0}$ is ostensibly not even present, although some site-specific configuration of $\mathrm{Au}$ atoms would be a possibility. However, further investigation of the behaviour of $\mathrm{Au}(\mathrm{OH})_{3}$ under reaction conditions is probably wise, since $\mathrm{Au}(\mathrm{OH})_{3}$ may undergo a reversible in situ reduction to gold nano-particles during the actual test of catalytic activity.

The availability of a geometric, site-specific model based on $\mathrm{Au}^{+} \mathrm{OH}^{-}$certainly permits an explanation of the high catalytic activity in all the diverse material forms of gold that have exhibited catalytic activity. However, if we accept the explanation that the activity is derived from some special geometric configuration of low-coordinated $\mathrm{Au}$ atoms (presumably always surrounded by a loosely bound layer of adsorbed species, and always amplified by a large specific surface area and small particle size [17]), then the final difficulty that must be accounted for is the matter of turnover frequencies (TOF) per surface atom. All else being equal, the number of special catalytic sites per unit of surface area should be constant in this model, and the TOF per surface $\mathrm{Au}$ atom should not be a function of particle size. In fact, some measurements of TOF have shown a very pronounced increase in activity for particle sizes below $2 \mathrm{~nm}$ (Figure 5). Evidently, use of the geometric model would require the simultaneous acceptance that the distribution of special sites per unit surface area depends sensitively on the material properties of the gold particles or surfaces.

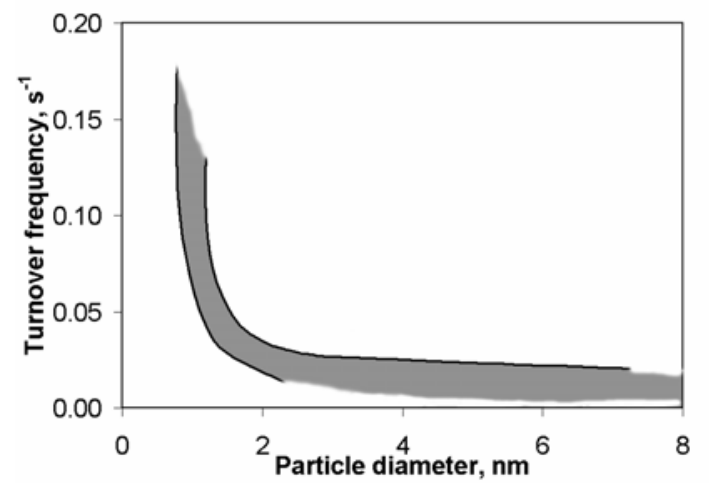

Figure 5. Scatter-band of measured turnover frequencies of gold nano-particles in the oxidation of $C O$, as a function of particle size. (redrawn after Haruta et al.[51]).

\section{CONCLUSIONS}

Gold-based catalysts have some unusual and useful features, in particular their high activity at comparatively low temperatures and their tolerance to humidity. In general, gold's efficacy as a catalyst is believed to be the result of its very low chemical reactivity which ensures that adsorbed reacting species are for the most part only weakly bound. The special, low reactivity of gold follows from its rather inert bulk properties, so that catalytically useful surfaces are most readily achieved only when the gold is exposed as nano-particles or nano-porous surfaces. The explana- 
tion for the special activity of the gold in these states is less well established, and the actual mechanism of the catalysed reactions not known with certainty. It was shown that few of the proposed mechanisms are able to explain all aspects of catalysis by gold, and the only hypothesis which is overarching is that the catalytic activity is the result of some special site on the gold, the density of which is highly sensitive to material properties, and the effect of which is amplified in a geometric fashion by expression in materials of very high specific surface areas. In this explanation, the role of the oxide support and of gold particle size and structure is indirect, and they would serve mainly to modulate the specific surface area of the gold, and the electronic configuration of its special surface sites.

\section{REFERENCES}

1. G.C. Bond: Gold Bulletin, 2001, vol.34(4), pp.117-119.

2. M. Haruta, H.Sano, and T. Kobayasi: Method for manufacture of catalyst composite having gold or mixture of gold with catalytic metal oxide deposited on carrier, US Patent 4698324, 1987.

3. M. Haruta, T. Kobayashi, H. Sano, and M. Yamada: Chemistry Letters, 1987, pp.405-408.

4. G.J. Hutchings: J. Catalysis, 1985, vol.96, pp.292295.

5. M.M. Schubert, S. Hackenberg, A.C. van Veen, M. Muhler, V. Plzak, and R.J. Behm: J. Catalysis, 2001, vol.197, pp.113-122.

6. D. Thompson: Gold Bulletin, 1999, vol.32(1), pp.12-19.

7. M. Valden., X. Lai, and D.W. Goodman: Science, 1998, vol.281, pp.1647-1650.

8. B.E. Salisbury, W.T. Wallace, and R.L. Whetten: Chemical Physics, 2000, vol.262, pp.131-141.

9. D. Thompson: Gold Bulletin, 1998, vol.31(4), pp.111-118.

10. L. Prati and G. Martra: Gold Bulletin, 1999, vol.32(3), pp.96-101.

11. Y. Yuan, A. Kozlova, K. Asakura, H. Wan, K. Tsai, and Y. Isawa: J. of Catalysis, 1997, vol. 170, pp.191-199.

12. H.S. Oh, J.H. Yang, C.H. Costello, Y.M. Wang, S.R. Bare, H.H. Jung, and M.C. Kung: J. of Catalysis, 2002, vol.210, pp.375-386.
13. S. Taylor, R. Meyer, I. Klingbiel, L. Glaner, A. Bollman, and E. van der Lingen, in New Industrial Uses for Gold 2001: Catalytic Gold, Cape Town, April 2001, p.41.

14. D. Andreeva: Gold Bulletin, 2002, vol. 35(3), pp. $82-88$.

15. G.R. Bamwenda, S. Tsubota, T. Nakamura, and M. Haruta: Catalysis Letters, 1997, vol. 44(1-2), pp.83-87.

16. Y.Z. Yuan, K. Asukura, H.L. Wan, K. Tsai and Y. Iwasawa: Catalysis Letters, 1996, 42(1-2), pp.1520.

17. A. Wolf and F. Schüth: Applied. Catal. A: General, 2002, vol.226, pp.1-13.

18. D.T. Thompson and G.C. Bond: Gold Bulletin, 2000, vol.33(3), pp.41-51.

19. G. Steinbach, E. van der Lingen, and M.B. Cortie: CATSA Catalysis 2002, 10-13 ${ }^{\text {th }}$ November 2002, Cape Town, South Africa.

20. N. Hodge, C.J. Kiely, R. Whyman, R. Siddiqui, G.J. Hutchings, Q. Pankhurst, F.E. Wagner, R. Rajaram, and S. Golunski : in New Industrial Uses for Gold 2001: Catalytic Gold, Cape Town, April 2001, p. 20 .

21. R. Grisel, K.J. Westrate, A. Gluhoi, and B.E. Nieuwenhuys: Gold Bulletin, 2002, vol.35(2), pp.39-45.

22. S. Taylor, R. Meyer, and E. van der Lingen: Microscopy Society of Southern Africa Proceedings, 2001, vol. 31, p.35

23. B. Grigorova, J. Mellor, A. Palazov, F. Greyling: Selective catalytic oxidation of $\mathrm{CO}$ in presence of $\mathrm{H}_{2}$, Patent PCT/IB00/00390, 2000.

24. T. Hayaski, K. Tanaka, and M. Haruta: J. of Catalysis, 1998, vol.178, pp.566-575.

25. D.A.H. Cunningham, W. Vogel, R.M. TorresSanchez, K. Tanaka, and M. Haruta: J. Catalysis, 1999, vol.183, pp.24-31.

26. K. Tanaka, T. Akita, D.A.H. Cunningham, S. Tsobota, et al.: Structural analyses and characterization of gold catalysts, Report of the Osaka National Research Institute, No.393, 1999, Osaka, Japan, pp.11-35.

27. D. Fischer, W. Andreoni, A. Curioni, H. Grönbeck, S. Burkart, and G. Ganteför: Chemical Physics Letters, 2002, vol.361, pp.389-396. 
28. A. Ueda and M. Haruta: Gold Bulletin, 1999, vol. 32(1), pp.3-11.

29. K. Ruth, M. Hayes, R. Burch., S. Tsobota, and M. Haruta: Appl. Catalysis B: Environmental, 2000, vol. 24, pp.L133-L138.

30. F. Besenbacher, I. Chorkendorff, B.S. Clausen, B. Hammer, A.M. Molenbroek, J.K. Nørskov and I. Stensgaard: Science, 1998, vol.279, pp.1913-1915.

31. H.H. Read: Rutley's Elements of Mineralogy, Thomas Murby \& Co, London, $26^{\text {th }}$ Edition, 1970.

32. C.L. Cleveland, U. Landman, T.G. Schaaf, and M.N. Shafigullin: Phys. Rev. Letters, 1997, vol.79, pp.1873-1876.

33. A.L. Mackay: Acta Cryst., 1962, vol.15, pp.916918.

34. W. Eberhardt: Surface Science, 2002, vol.500, pp.242-270.

35. T.X. Li, S.Y. Yin, Y.L. Ji, B.L. Wang, G.H. Wang, and J.J. Zhao: Physics Letters A, 2000, vol.267, pp.403-407.

36. J.M. Soler, I.L. Garzón, and J.D. Joannopoulis: Solid State Communications, 2001, vol. 117, pp.621-625.

37. H.B. Liu, J.A. Ascencio, M. Perez-Alvarez, and M.J. Yacaman: Surface Science, 2001, vol.491, pp.88-98.

38. I.L. Garzón, K. Michaelian, M.R. Beltrán, PosadaAmarillas, A., P. Ordejón, E. Artacho, D. SánchezPortal, and J.M. Soler: Physical Review Letters, 1998, vol.81(8), pp.1600-1603.

39. A.C. Templeton, W.P. Wuelfing, and R.W. Murray: Acc. Chem. Res, 2000, vol.33, pp.27-36.

40. L.R. Wallenberg, J.O. Bovin, and G. Schmid: Surface Science, 1985, vol.156, pp.256-264.

41. J. Turkevich: Gold Bulletin, 1985, vol.18(3), pp.86-91.

42. U. Heiz, A. Sanchez, S. Abbet, W.D. Schneider: Chemical Physics, 2000, vol.262, pp.189-200.

43. N.N. Greenwood and A. Earnshaw, Chemistry of the Elements, Butterworth Heinemann, Oxford UK, 1984.

44. G. Mills, M.S. Gordon, and H. Metiu: Chemical Physics Letters, 2002, vol.359, pp.493-499.
45. A. Sanchez, S. Abbot, U. Heiz, W.D. Schneider, H. Häkkinen, R.N. Barnett, and U. Landman: $J$. Phys. Chem A, 1999, vol.103, pp.9573-9578.

46. P. Buffet, and J.P. Borel: Phys. Rev. A., 1976, vol.13, pp.2287-2292.

47. G. Bilalbegović: Solid State Communications, 2000, vol.115, pp.73-76.

48. K. Dick, T. Dhanasekaran, Z. Xhang, and D. Meisel: J. Am. Chem. Soc, 2002, vol.124(10), pp.2312-2317.

49. P. Poizot, S. Laruelle, S. Grugeon, L. Dupont, and J.M. Tarascon: Nature, 2000, vol.407, pp.496-499.

50. J. Doye: www-wales.ch.cam.ac.uk/ jon/research /cluster structure.html, accessed $25^{\text {th }}$ November 2002.

51. M. Haruta, S. Tsubota, T. Kobayashi, H. Kageyama, M.J. Genet, and B. Delmon: J. of Catalysis, 1993, vol. 144, pp.175-192.

52. C.-H. Lin, S.-H. Hsu, M.-Y. Lee, and S.D. Lin: $J$. of Catalysis, 2002, vol.209, pp. 62-68.

53. Y. Iizuka : in New Industrial Uses for Gold 2001: Catalytic Gold, Cape Town, April 2001, p.25.

54. E. van der Lingen, M.B. Cortie, and L. Glaner: Catalyst and method of producing a catalyst, SA Patent 2001/5816, 2001.

55. G.J. Hutchings: in New Industrial Uses for Gold 2001: Catalytic Gold, Cape Town, April 2001, p.23.

56. M. Johnson, electronic magazine, Frontiers, Issue 4, August 2002, published on www.bp.com, accessed $24^{\text {th }}$ December 2002. 